\title{
ESTRATÉGIAS DE MARKETING DIGITAL PARA A ALAVANCAGEM EM E-COMMERCE: UM ESTUDO DE CASO EM UMA EMPRESA DE BRUSQUE
}

\author{
Waleska Turro Marquez ${ }^{1}$, Karin Vieira da Silva ${ }^{2}$, \\ Anderson Sasaki Vasques Pacheco ${ }^{3}$, Raul Otto Laux ${ }^{4}$ \\ ${ }^{1}$ waleska_turro@unifbe.edu.br \\ 2vieira.karin@gmail.com \\ ${ }^{3}$ sasaki.anderson@gmail.com \\ 4raulaux@unifebe.edu.br
}

\section{Resumo}

O e-commerce ou comércio eletrônico surge como uma ferramenta estratégica para auxiliar as empresas a ampliarem a sua rede de clientes, ao propiciar uma melhor qualidade nas vendas e oferecer aquilo que de fato precisam, e, consequentemente, aumentar os lucros das organizações. O objetivo deste trabalho é identificar as estratégias utilizadas para alavancar o e-commerce de uma empresa do ramo de confecção de cama e mesa de Brusque. Para sustentar o estudo, a fundamentação teórica apresentou os seguintes temas: e-commerce, e-commerce no Brasil e Marketing Digital. Por meio de pesquisas bibliográficas e entrevistas, verificamos que as principais estratégias utilizadas pela empresa foram: tornar os preços acessíveis, obter qualidade do produto, criação de uma plataforma virtual de fácil navegação, evidenciar vantagens financeiras ao cliente (frete grátis, cupons de desconto), participação em marketplaces nacionais, além de criar redes sociais como Instagram e Facebook, fazendo postagens diárias para aumentar o contato com o cliente. Além disso, foram encontrados indicativos de que o apoio de um serviço especializado pode contribuir positivamente para alavancar as vendas de um e-commerce, dado que as ações implementadas resultaram em aumento de vendas e faturamento. Após seguir esses passos, verificamos que a empresa passou a ter um maior número de visitantes e compradores em seu site.

Palavras-chave: E-commerce. Marketing digital. Internet.

\section{DIGITAL MARKETING STRATEGIES FOR E-COMMERCE LEVERAGE: A CASE STUDY IN A BRUSQUE COMPANY}

\section{Abstract}

E-commerce or e-commerce emerges as a strategic tool to help companies expand their customer network by providing better quality sales and delivering what they really need, and thereby increase the profits of organizations. The objective is to identify the strategies used to leverage the e-commerce of a home textile industry of Brusque. To support the study, the theoretical foundation presented the following themes: E-commerce, E-commerce in Brazil and Digital Marketing. Through bibliographic research and interviews, we verified that the main strategies used by the company were: adjust prices, obtain product quality, create an environment to facilitate navigation, develop financial advantages to the customer (free shipping, discount coupons), participation in marketplaces, create social networks like Instagram and Facebook, post in social media daily, to increase contact with the client. In addition, it was found that the support of a specialized service can positively contribute to leverage sales of an e-commerce website, since the implemented actions resulted in increased

R. Eletr. do Alto Vale do Itajaí - REAVI, v. 7, n. 11, p. 01-09, dez., 2018 ISSN: 2316-4190, DOI: $10.5965 / 2316419007112018070$ 


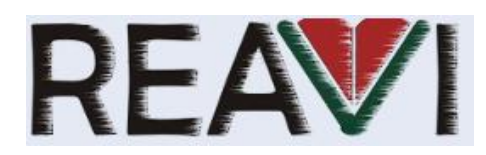

\section{Universidade do Estado de Santa Catarina \\ Centro de Educação Superior do Alto Vale do Itajaí}

sales and profit. After following these steps, we find that the company has a greater number of visitors and buyers in their website.

Keywords: E-commerce. Digital Marketing. Internet.

\section{Introdução}

O uso da tecnologia da informação (TI) vem crescendo amplamente nas organizações, e, com isso, a procura pelas compras via internet tem aumentado gradativamente ao longo do tempo. Um dos principais fatores para esse crescimento é a comodidade que proporciona e o fato de as pessoas não terem mais tempo para sair de casa e ir até uma loja física (SANTOS, 2018).

Nesse cenário, destaca-se o e-commerce ou comércio eletrônico, que surge como uma ferramenta estratégica para auxiliar as empresas a ampliarem a sua rede de clientes, propiciarlhes uma melhor qualidade nas vendas e oferecer-lhes aquilo que fato eles precisem e, dessa forma, aumentar os lucros das organizações. Na literatura, há diversas interpretações sobre o conceito de e-commerce. O'brien (2004, p.205), define e-commerce como "a compra e a venda por meios digitais." Servindo como reforço, Idesis (2010, p.1) conceitua "e-commerce como o conjunto de atividades comerciais que acontecem on-line".

Tendo em vista que o e-commerce é um dos setores que hoje mais cresce no mercado, ressalta-se que o faturamento desse segmento deve registrar um crescimento nominal de 12 por cento no Brasil em 2017, conforme mostrou o relatório Webshoppers da Ebit 2016. Nesse contexto, levanta-se o seguinte problema de pesquisa: Quais são as estratégias utilizadas para alavancar o e-commerce de uma empresa do ramo de confecção de médio porte da região de Brusque?

A pesquisa tem como objetivo geral identificar as estratégias utilizadas para alavancar o e-commerce de uma empresa do ramo de confecção de cama e mesa de Brusque. Para o alcance do objetivo geral, os seguintes objetivos especificos foram delineados: i) identificar as estratégias utilizadas pela empresa em sua plataforma de e-commerce; ii) identificar as estratégias utilizadas pela empresa em suas mídias sociais; iii) identificar as estratégias utilizadas pela empresa nas plataformas de busca online; iv) Identificar os impactos dessa ações.

Para a sustentação da pesquisa foi levantado na literatura os principais assuntos que rondam a temática do e-commerce, a sua situação no Brasil e o marketing digital. Estes serão apresentados a seguir.

\section{Fundamentação Teórica}

\subsection{E-commerce}

O e-commerce é uma ferramenta muito utilizada nos dias de hoje, contudo, ainda há uma grande dispersão conceitual sobre os seus limites e possibilidades. É possível encontrar na literatura, por exemplo, diversas definições sobre esta ferramenta.

De acordo com Parente (2000 p. 15), "o e-commerce é um formato de varejo, que pela internet, oferece produtos e serviços, facilitando para que os consumidores comprem e completem a transações por meio de um sistema eletrônico interativo". Um e-commerce ou loja virtual é um conjunto de sistemas que interagem com o cliente de uma forma que efetive um processo de compra. É utilizado para que as empresas mostrem os seus produtos a milhares de internautas que estão conectados diariamente. Conforme Nakamura (2001 p. 31), entende-se por comércio eletrônico "toda atividade compra e venda realizada com auxílio de recursos eletrônicos".

R. Eletr. do Alto Vale do Itajaí - REAVI, v. 7, n. 11, p. 01-09, dez., 2018 ISSN: 2316-4190, DOI: $10.5965 / 2316419007112018070$ 
Segundo Cateora (2007, p. 425-426):

$\mathrm{O}$ e-commerce é mais desenvolvido nos Estados Unidos que no resto do mundo, muito por conta do vasto número de pessoas que possuem computadores particulares e ao baixo custo do acesso à Internet, que se encontra em qualquer lugar. Apesar disso, algumas estimativas europeias, apontam a Europa como $26^{\circ}$ maior consumidor de $e$ commerce que os americanos. Também ressalta que a Internet finalmente põe o consumidor no controle do mercado.

A conformidade, a rapidez e o custo são algumas vantagens para os consumidores que fazem uso do e-commerce. Os consumidores conseguem efetuar a compra de qualquer tipo de produto, a qualquer hora do dia e em qualquer lugar do mundo. Com o avanço da tecnologia, é possível avaliar o produto e até comparar preços com outras empresas, promovendo a competitividade (YESIL, 2000). Para este autor, alguns elementos são essenciais para que uma loja virtual seja bem-sucedida, a saber:

\footnotetext{
1. Fixar as metas corretas para sua loja virtual

2. Compreender o processo de vendas ao consumidor e criar um ambiente apropriado ao oferecimento de seus produtos e serviços online

3. Aprender a conhecer seus clientes e, desse modo, gerar negócios repetidos e adaptar sua loja nos locais certos, o que leva o crescimento das vendas

4. Receber pagamentos na própria loja virtual (YESIL, 2000, p. 37).
}

Mesmo que tenha muitas vantagens em seu uso, ainda existem várias barreiras que travam o crescimento das compras on-line, ou seja, existem fatores que podem influenciar negativamente na decisão de compra do consumidor.

De acordo com Malleta (2013, p. 19), "a maior barreira para compra on-line de produtos é a falta de contato físico com o produto. O motivo mais forte é o fato do consumidor não conseguir pegar ou sentir ou testar o produto na hora da compra". Assim, os ambientes de venda online precisam buscar soluções criativas para superar esse entrave.

As cores são uma das primeiras razões que despertam vontade no consumidor em comprar determinado produto. Além disso, elas podem contribuir para o reconhecimento de uma marca. Entretanto, cabe o gestor de cada local identificar qual o significado das cores, pois aspectos sociais podem influenciar na psicologia das cores (HELLER, 2013). Portanto, as estratégias para aproximar produtos e clientes devem ser pensadas dentro do contexto de cada organização.

Além das cores, o comportamento do consumidor é influenciado por outros motivos, como: o design, o texto e a velocidade do site. Bellini $(2017$, p. 1) salienta que a taxa de conversão médio das páginas de e-commerce, no Brasil, é de $1,4 \%$, sendo que a maior taxa é encontrada no Estado de Santa Catarina. Assim, o desenvolvimento de um ambiente de $e$ commerce deve atentar para a satisfação das necessidades dos clientes, de modo a oferecer uma boa experiência de compra e a construção de relacionamentos duradouros.

De acordo com a WebJump (2017), o Brasil é um dos países que registra as maiores taxas de crescimento em e-commerce no mundo e, apesar de grandes nomes estarem presentes na internet, com enormes portais de vendas, a grande fatia responsável por este crescimento espantoso são as pequenas e médias lojas virtuais. A seguir, serão apresentadas mais informações sobre a situação do e-commerce no Brasil.

\subsection{Situação do E-commerce no Brasil}

No Brasil, de acordo com Moraes (2016), foi a empresa "Magazine Luiza", uma das principais responsáveis por iniciar empreendimentos online, especificamente, em lojas virtuais. Inicialmente, esse sistema de vendas era sustentado por meio de terminais, entretanto, com

R. Eletr. do Alto Vale do Itajaí - REAVI, v. 7, n. 11, p. 01-09, dez., 2018 ISSN: 2316-4190, DOI: $10.5965 / 2316419007112018070$ 
aprimoramento contínuo, ele adquiriu o formato amplamente tecnológico em que se encontra atualmente. Ainda segundo Moraes (2016), os terminais utilizados pela empresa Magazine Luiza não tinham conexão com a internet, pois a mesma só foi liberada para fins comerciais no Brasil a partir da década de 90. Portanto, a primeira empresa a operar um e-commerce com o uso da internet foi a Brasoftware em 1996.

Desde então, o e-commerce, no Brasil, vem passando por períodos de crescimento contínuo. A partir da Figura 1, a seguir, pode-se perceber que para o ano de 2017 espera-se um crescimento no faturamento com vendas via e-commerce de aproximadamente $11 \%$.

Segundo Pinho (2000, p. 219), "os consumidores virtuais brasileiros não são muito diferentes em comportamento dos compradores do restante do mundo, mas gastam mais comprando em lojas estrangeiras do que nas nacionais".

Figura 1 - Evolução do Faturamento do E-commerce no Brasil.

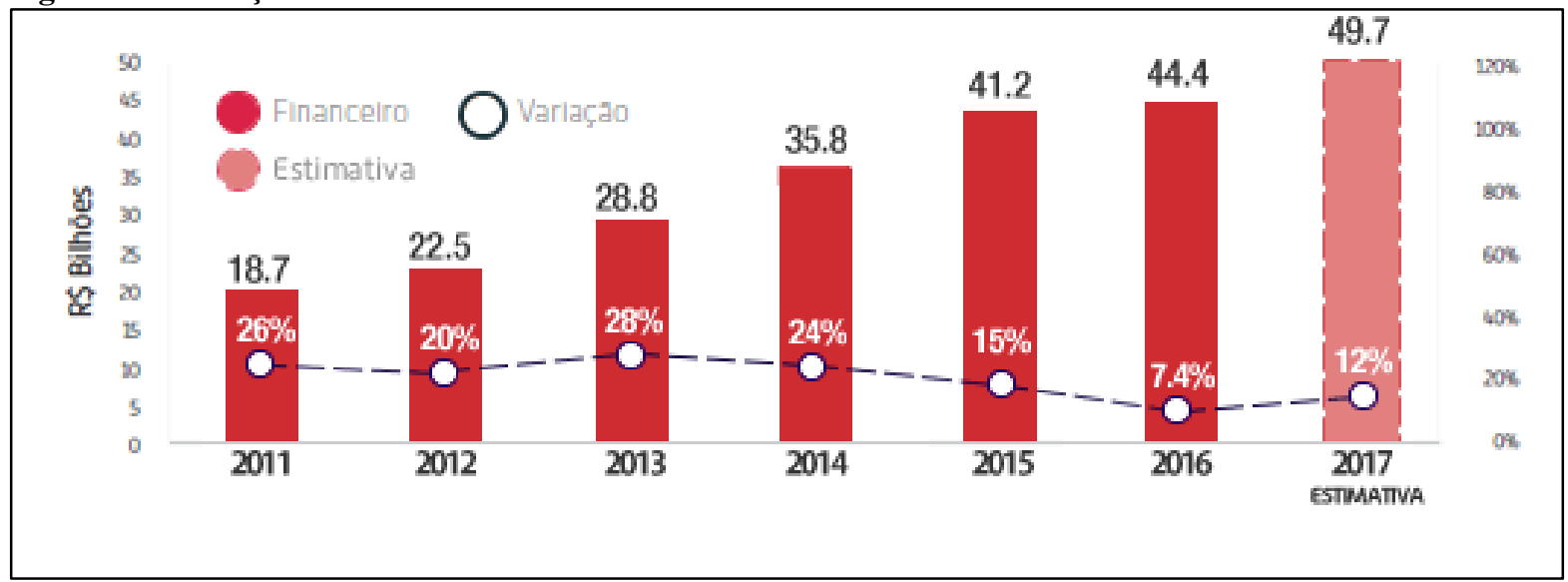

Fonte: EBIT Informação (2017).

Na Figura 2, pode-se identificar como funciona o mercado de vendas eletrônicas no Brasil, no top 3 destaca-se, Moda e Acessórios, Cosméticos e Saúde seguidos pelos eletrodomésticos.

Conforme Maletta (2013), o setor de moda e vestuário tem se mantido em primeiro no ranking de mais vendidos, impulsionado pelas mulheres jovens. Em 2011, segundo ele, mulheres de 18 a 21 anos ocupavam $25 \%$ no ranking de consumidores e, em 2013 , tal percentual chegou aos $40 \%$.

Figura 2 - Categorias mais vendidas em 2014 - em volumes de pedidos.

R. Eletr. do Alto Vale do Itajaí - REAVI, v. 7, n. 11, p. 01-09, dez., 2018 ISSN: 2316-4190, DOI: 


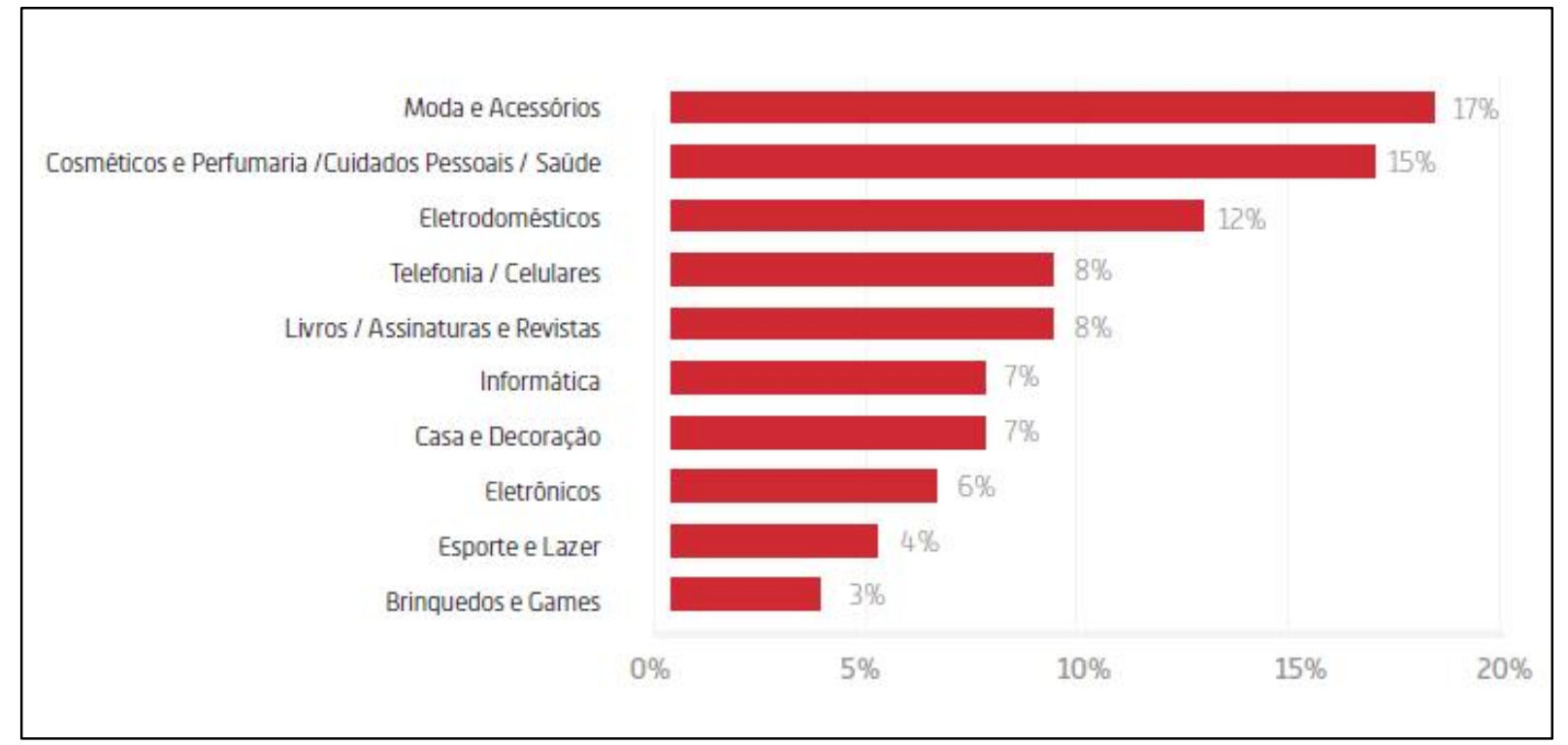

Fonte: ABIHPEC (2016).

De acordo com o SEBRAE (2016), a maior segurança e confiança no momento da compra, as plataformas de negociação derivadas de novos canais como o social commerce (comércio proveniente de plataformas sociais), reformas governamentais que contribuíram para o incentivo ao e-commerce, aumento do nível de bancarização, além de um maior uso dos meios de pagamentos eletrônicos, como os cartões de crédito, estão entre os fatores que contribuíram para o crescimento do e-commerce no Brasil.

No âmbito das vendas online, a forma de desenvolvimento de estratégias de marketing ganhou um novo formato, adaptado ao universo virtual e a um novo perfil de consumiro. Tratase do marketing digital, que será apresenta a seguir.

\subsection{Marketing Digital}

Antes de adentrar à temática específica do marketing digital, julga interessante ressaltar o entendimento de marketing, de uma forma geral. Para Kotler (2008, p.126),

(...) marketing é atividade humana dirigida para satisfazer necessidades e desejos por meio de troca. A consistência do marketing, são ações que levam a construção e manutenção do ato da troca, com um público-alvo de algum produto, serviço, ideia ou outro objetivo. O principal objetivo é mais que atrair novos clientes e criar transações, é manter os clientes e ampliar os negócios com a empresa.

O marketing é voltado para atender as necessidades e desejos das pessoas, e, antes de tudo, deve se levar em conta um aspecto muito importante: conhecer o seu público-alvo, o colocando como centro de qualquer ação de marketing, a fim de satisfazê-lo, pois, assim, as estratégias serão mais efetivas. Caso o seu público-alvo mude, as ações de marketing também precisam mudar (KOTLER, 2008).

Já o marketing digital, de acordo com Gabriel (2010) surgiu nos anos 90, com a primeira versão de Internet, um pouco diferente da qual conhecemos hoje. Apesar de não permitir que os usuários interagissem com páginas da $w e b$ de maneira ativa, deixava que eles encontrassem informações em um sistema de busca simples. Foi nesse início da Internet que o termo "marketing digital" surgiu. Antes disso, as empresas usavam, no máximo, seu site institucional, o consumidor recebia passivamente o conteúdo, sem interação próxima entre as duas partes.

R. Eletr. do Alto Vale do Itajaí - REAVI, v. 7, n. 11, p. 01-09, dez., 2018 ISSN: 2316-4190, DOI: 
Na opinião de Gabriel (2010, p.104) "o marketing que utiliza estratégias em algum componente digital no marketing mix - produto, preço, praça ou promoção". Dessa forma, pode-se dizer que o Marketing Digital é o bom e velho marketing só que trabalhado através de ferramentas digitais. Ou seja, é o conjunto de ações estratégicas aplicadas nos meios digitais (internet e tecnologias móveis), para conquistar e fidelizar clientes, elevando a participação da empresa no mercado (NOGUEIRA, 2014).

Foi apenas nos anos 2000, que o marketing digital passou a ser mais próximo do modelo que conhecemos hoje. Em 2002 a internet começa a se popularizar no Brasil, ainda sob os efeitos da bolha. Entretanto, os investimentos ainda eram escassos, sendo que de 2008 para frente, pode-se verificar que a grande ascensão das vendas de computadores, celulares e a introdução do marketing digital como conhecemos hoje (CINTRA ,2010).

Tendo realizado os principais apontamentos teóricos sobre a temática que circunda a presente pesquisa, parte-se, a seguir, para o estudo de caso.

\section{Metodologia}

A pesquisa tem abordagem qualitativa, que é um método útil e necessário para identificar e explorar os significados dos fenômenos estudados e as interações que estabelecem, possibilitando estimular o desenvolvimento de novas compreensões sobre a variedade e a profundidade dos fenômenos sociais (BARTUNEK; SEO, 2002).

Com relação aos objetivos do trabalho, trata-se de uma pesquisa exploratória, que ocorre por meio de pesquisa bibliográfica e documental. De acordo com Minayo (2010. p.47), "a pesquisa exploratória é aquela que se aplica ao estudo da história, das relações, das representações, das crenças, das percepções e das opiniões, produtos das interpretações que os humanos fazem a respeito de como vivem, constroem seus artefatos e a si mesmos, sentem e pensam".

Referente aos procedimentos, este artigo se encaixa na modalidade de pesquisa bibliográfica, que consiste em um "estudo sistematizado desenvolvido com base em material publicado em livros, revistas, jornais, redes eletrônicas, isto é, material acessível ao público em geral". (VERGARA, 2013, p. 43).

De acordo com Gil (2002), para a delimitação de estudos qualitativos, é indicado o uso de amostras não probabilísticas, que consiste em identificar e selecionar uma amostra na qual seja possível obter as informações necessárias ao estudo. Assim, a presente pesquisa abrange a empresa Alfa, confecção do ramo de cama e mesa, fundada no ano de 2001 e localizada na cidade de Brusque.

Para a coleta dos dados obtidos para a construção do trabalho, foram utilizados como instrumentos a pesquisa bibliográfica e documental nos principais sites, artigos e revistas voltados para o e-commerce. Para Duarte (2002, p. 68), "a definição do objeto de pesquisa assim como a opção metodológica constituem um processo tão importante para o pesquisador quanto ao texto que se elabora no final".

Em complemento, foram realizadas entrevistas semi-estruturadas, com dois indivíduos centrais para a pesquisa: o proprietário da empresa "Alfa" e o responsável pelo delineamento das estratégias de marketing - um consultor da empresa de marketing e propaganda. Esses entrevistados foram escolhidos por estarem diretamente relacionados com as estratégias de marketing utilizadas pela organização estudada, permitindo, dessa forma, conhecer o processo de forma mais aprofundada.

A análise de dados foi realizada por meio da análise de conteúdo, tendo como base os objetivos da presente pesquisa. Além disso, recorreu-se ao confronto entre a teoria e a prática encontrada no estudo empírico.

R. Eletr. do Alto Vale do Itajaí - REAVI, v. 7, n. 11, p. 01-09, dez., 2018 ISSN: 2316-4190, DOI: $10.5965 / 2316419007112018070$ 


\section{Estudo de Caso}

Nessa seção será apresentada, inicialmente, uma análise da situação atual da empresa estudada. Em seguida apresentaremos os dados do e-commerce da organização antes e depois da contratação da empresa de marketing.

\subsection{Histórico da Empresa}

A Empresa "Alfa", é uma empresa do ramo de confecção de cama e mesa, localizada na cidade de Brusque e fundada no ano de 2001. Atualmente a organização conta com 80 colaboradores diretos, e cerca de 100 indiretos. A empresa possui representantes físicos em todo o Brasil, porém tem seu maior destaque nos três estados do sul do País. Entre seus principais clientes, destacam-se as Lojas Havan e redes de supermercados como Giassi e Bistek.

No ano de 2015 foi quando se iniciou o processo de implantação do e-commerce na empresa. Foi um processo lento, pois, a organização conta com um mix de produtos bem amplos. Depois de estruturado e desenvolvido, a plataforma de e-commerce foi ao ar, mas havia pouca venda, pois não existia nenhum conhecimento na área de vendas online, foi quando ficou clara a necessidade de ajuda.

No fim do ano de 2016, surgiu a proposta da integração do site organizacional com outros marketplaces, ou seja, instituições que emprestam seu site para que empresas menores anunciem seus produtos em troca de comissão sobre as vendas, exemplos desse tipo de organização são o Walmart, mercado livre, submarino, entre outros. Com essa integração, a empresa teve um aumento significativo no número de pedidos, pois, até então, o e-commerce apresentava baixos níveis vendas. Mas, fora o faturamento dos marketplaces, o e-commerce continuava com o faturamento baixo.

Hoje, com a contratação da agência de marketing, o e-commerce está em processo de mudanças. Estão sendo realizados trabalhos com o foco de atrair mais visitantes e mais visualizações, buscando aumentar as taxas de conversão, ou seja, transformar as visitas na loja virtual em vendas.

\subsection{Análise da Situação Atual da Empresa}

O e-commerce da empresa possui parceria com marketplaces, na qual dentro de outros sites a organização vende seus produtos. São três lojas parceiras, que cobram uma taxa de comissão para comercializar os produtos. Para a organização é muito vantajoso, pois, são as principais lojas online hoje no mercado. Assim, é possível divulgar sua marca e atrair clientes através da divulgação em sites com maior número de usuários.

Por outro lado, a empresa possui sua própria loja, que, por sua vez, precisa de investimentos com marketing, propagandas, etc. Entretanto, como está no começo ainda, todo esse processo está em construção e passa por várias modificações, visando atrair mais visitantes e, consequentemente, aumentar seu faturamento.

A empresa conta com uma agência de marketing e propaganda, para auxiliar nesse processo. Tendo estes profissionais como parceiros, eles podem direcionar o seu público-alvo, fazer campanhas promocionais, anúncios, etc., coisas que antes o e-commerce não tinha.

\subsection{Diagnóstico: E-commerce da Empresa "ALFA"}

Com base nos dados coletados, é possível verificar que a empresa possui a visão de que o e-commerce é uma ferramenta muito importante para o seu desenvolvimento, e busca formas

R. Eletr. do Alto Vale do Itajaí - REAVI, v. 7, n. 11, p. 01-09, dez., 2018 ISSN: 2316-4190, DOI: 
para que ele seja desenvolvido de forma mais rápida e eficaz possível. Segundo o proprietário da empresa "Alfa":

A ideia da implantação de um e-commerce já estava em nossos planos há muito tempo, porém, sempre fomos muito cautelosos quanto a isso. Devido a nossa base de clientes serem praticamente toda formada por clientes lojistas, no início, achamos que a implantação de uma loja virtual que atendesse diretamente o consumidor final poderia trazer problemas com nossos clientes atacadistas. Porém, com o passar do tempo fui percebendo que praticamente todos os nossos concorrentes tinham essa ferramenta, $\mathrm{e}$ que ela estava cada vez crescendo mais, foi então que decidimos entrar neste mercado. (ENTREVISTADO 1).

A conformidade, a rapidez e o custo são algumas vantagens para os consumidores que fazem uso do e-commerce. Os consumidores conseguem efetuar a compra de qualquer tipo de produto, a qualquer hora do dia e em qualquer lugar do mundo. Com o avanço da tecnologia, é possível avaliar o produto e até comparar preços com outras empresas, promovendo a competitividade (YESIL, 2000).

Como vimos na pesquisa, os clientes buscam informações de qualidade e características tanto do produto como do próprio vendedor, justamente nos comentários e avaliações feitas por compradores que já receberam seu produto, isso pode definir a compra ou levar o cliente a cancelar a mesma. E fazer com que o cliente se sinta confiante para comprar é o objetivo das mudanças no e-commerce, de acordo com o proprietário da empresa:

Hoje em dia todo mundo tem um celular, computador e acesso à internet, e o que atrai o cliente é a comodidade de poder comprar a qualquer hora, em qualquer lugar, sem filas e sem nenhum contato pessoal. Então, entendo que esse seja o futuro do comércio em todos os setores, desde alimentício até mesmo automobilístico. Então, o site tem que ser tratado como uma vitrine de loja, deve ser atrativo, as informações devem ser de fácil entendimento e, claro, um preço competitivo e produtos com qualidade. Então, essa é a importância, trazer confiança para que o cliente compre sem medo. (ENTREVISTADO 1).

De acordo com Valente (2017) "Um relatório sobre economia digital divulgado em outubro de 2017 pela Conferência das Nações Unidas sobre Comércio e Desenvolvimento (UNCTAD, na sigla em inglês) apontou o Brasil em quarto lugar no ranking mundial de usuários de internet. Com 120 milhões de pessoas conectadas a rede". Além disso, atualmente, o e-commerce pode abranger praticamente todas as áreas do comércio, e com alguns ajustes as perspectivas da empresa "Alfa" podem ser alcançadas, de acordo com o Entrevistado 2:

Atualmente, o comércio eletrônico abrange praticamente todos os segmentos, desde moda e cosméticos, até produtos alimentícios. As perspectivas para o e-commerce da empresa Alfa são os melhores possíveis. Hoje estamos em fase de estruturação, um processo um tanto quanto lento, pois são muitos detalhes que são de grande importância para o resultado final. A empresa conta com um mix de produto bem diversificado e com um preço bem atrativo para o cliente, em relação aos concorrentes. Portanto, quando todos os pontos de melhora forem finalizados, com certeza o e-commerce da empresa Alfa terá um bom nível de faturamento com relação aos números antes de começarmos o nosso trabalho de marketing digital com a empresa (ENTREVISTADO 2).

Porém, são vários os fatores que influenciam o cliente na hora da compra, pois não basta apenas atrair a atenção do cliente, mas é também preciso converter isso em vendas. Ressaltase, novamente, que a taxa de conversão média no Brasil é de apenas 1,4\%, sendo que o Estado de Santa Catarina, esse valor chega a 1,7\% (BELLINI; SALVADOR, 2017). Dessa forma, cabe ao gestor desenvolver ações para a conversão da compra, como observado nas entrevistas: 
Preços competitivos, opções de pagamento, cupons de desconto, frete grátis, informações claras, página rápida, são itens que levam o cliente a efetuar a compra. Criamos para a empresa Alfa, todos esses aspectos citados acima. Frete grátis nas compras acima de $\mathrm{R} \$ 300,00$ na região sul, $10 \%$ de desconto nas compras à vista, parcelamento em até $3 \mathrm{x}$ sem juros, aperfeiçoamos as informações para ficarem mais claras e de fácil entendimento do cliente (ENTREVISTADO 2).

Como citado pelo Entrevistado, o frete gratuito tem um grande impacto para o aumento das vendas da empresa. Esse tipo de promoção é de suma importância para o e-commerce nacional, 29,8\% dos pedidos captados, no ano de 2017, tiveram frete gratuito. Existem setores, como dos produtos para Casa, com uma maior dependência desse tipo de ação, com 57,4\% dos produtos vendidos com frete grátis (BELLINI; SALVADOR, 2017).

Grossmann (2013), baseado em dados fornecidos pelo Ibope diz que "as lojas virtuais obtiveram o maior tempo médio de visita, com 59 minutos, e os smartphones e tablets já representavam $65 \%$ e $34 \%$, respectivamente, dos aparelhos utilizados para busca de informações sobre produtos e serviços do e-commerce brasileiro". Nesse contexto, a empresa estudada está implementando as seguintes ações, visando atrair o público que utiliza tais ferramentas em suas compras:

Em breve estaremos fotografando alguns produtos da empresa, para que tenhamos imagens melhores e mais profissionais. Assim passar mais confiança para os clientes. Estaremos também, iniciando campanhas para o Blackfriday e para o natal. Serão usados produtos promocionais e com grande procura pelo cliente. Usaremos todos os meios de divulgação para essas campanhas. Acreditamos ter um fluxo de cliente significativo nestas datas. Convertendo o máximo possível em vendas (ENTREVISTADO 2).

Criar mecanismos que levem o cliente a finalizar a compra são muito importantes, pois pesquisas afirmam que as lojas virtuais tiveram 1,6 bilhão de visitas por mês, mas cerca de 25,9 milhões viraram compras, o que corresponde a 1,6\% do total. É o que mostra o estudo "Cenário do E-Commerce no Brasil (2017)", realizado pela plataforma de digital analytics da Netquest em parceria com a Braspag, empresa do grupo Cielo. Para tentar converter mais visitas em vendas a empresa de marketing implantou na empresa as seguintes mudanças:

As estratégias principais que utilizamos na empresa Alfa são:

* Criar descrições bem explicativas, que não sejam confusas, ou seja, que fiquem claras para o cliente;

* Deixar as imagens leves, para que a loja não demore a carregar. Quando um site demora a carregar, provavelmente o cliente não voltará novamente;

* Criar banners bem apresentados e atrativos para o cliente;

* Deixar os produtos bem posicionados, para que o cliente domine facilmente (ENTREVISTADO 2).

Com a contratação da empresa de marketing, mudaram também algumas características do e-commerce, e fizeram com que o mesmo ficasse mais atraente ao cliente, como identificou o Entrevistado 1, da empresa "Alfa":

As principais alterações que fizemos foram mudanças na forma de divulgar, com a criação da página no Facebook e Instagram, com postagens diárias. Criação de banners para datas comemorativas e fotos com mais qualidade.

Além da sincronização com diversas plataformas de vendas, como Mercado Livre, Casas Bahia, Walmart, entre outros. Essas plataformas ajudam nas vendas, pois todas elas passam mais credibilidade para o cliente na hora da compra (ENTREVISTADO 1).

R. Eletr. do Alto Vale do Itajaí - REAVI, v. 7, n. 11, p. 01-09, dez., 2018 ISSN: 2316-4190, DOI: $10.5965 / 2316419007112018070$ 
Sobretudo na primeira venda, pode-se dizer que a utilização de marketplaces é bemvinda. A empresa ao optar por essa estratégia, acaba indo ao encontro da maioria das empresas brasileiras. Destaca-se, portanto, que existe uma grande dependência dos e-commerce em marketplaces, em que quase $31,5 \%$ das vendas online são efetuadas neste canal (BELLINI; SALVADOR, 2017).

Além disso, pode-se observar, pela fala dos entrevistados, que a criação do Facebook e Instagram contribuem para o desenvolvimento do marketing de relacionamento. "Aproximadamente $77 \%$ dos clientes compraram somente uma vez e 5\% dos clientes compraram mais de 6 vezes." (BELLINI; SALVADOR, 2017, p.24). Entretanto, para os mesmos autores, o e-mail é o canal mais importante da fidelização. Aproximadamente $35 \%$ dos clientes que compram 2 ou mais vezes compram, por causa do mailing. Mesmo assim, as redes sociais são importantes para a fidelização do cliente, conforme Grossmann (2013, p.1):

Hoje em dia, além de outros fatores, é preciso estar atento às redes sociais, que formam uma parte importante da experiência de compra do adolescente no comércio eletrônico, procurando conteúdo e interatividade. Com relação ao Facebook, por exemplo, a maioria dos usuários têm entre 18 e 25 anos. No Twitter, os mais adeptos estão na faixa dos 26 a 34 anos. No entanto, esses usuários acessam as redes sociais pelo menos uma vez ao dia, e o tempo gasto online diariamente por este grupo é de 23 minutos, em média.

A agência de marketing também corrobora sobre a importância das redes sociais, sobretudo no campo do marketing:

Hoje as redes sociais estão muito presentes no nosso dia a dia, é um ponto essencial para o crescimento do e-commerce, tendo em vista que grande parte dos visitantes parte das redes sociais, além de trazer mais visibilidade da marca. Na empresa Alfa, foram criados perfis no Facebook e Instagram, lá respondemos todas as dúvidas e mensagens deixadas pelos clientes, postamos conteúdos diariamente, não só dos produtos, mas também dicas de uso, dicas de decoração, etc. Tanto do Facebook, como Instagram, impulsionamos anúncios e direcionamos para o público alvo da empresa. O resultado esperado é converter o máximo de cliques no site em vendas (ENTREVISTADO 2).

Quando questionado a respeito da questão do custo/benefício da contratação da agência de marketing, o proprietário da empresa "Alfa" afirma que:

Com certeza vale a pena, pois com essa ferramenta conseguimos atingir o consumidor final, e nos preços praticados nos produtos do e-commerce conseguimos incluir uma margem de $90 \%$ sobre o preço de custo. Então, temos uma boa margem para investir em ferramentas que irão aumentar o número de vendas. Então, mesmo que a margem de lucro diminua, o número de vendas aumentará, compensando assim o investimento (ENTREVISTADO 1).

Na Figura 3 podemos comparar o número de visitas antes e depois da contratação da agência de marketing: 
Figura 3 - Número de visitas ao site da empresa Alfa, no ano de 2018.

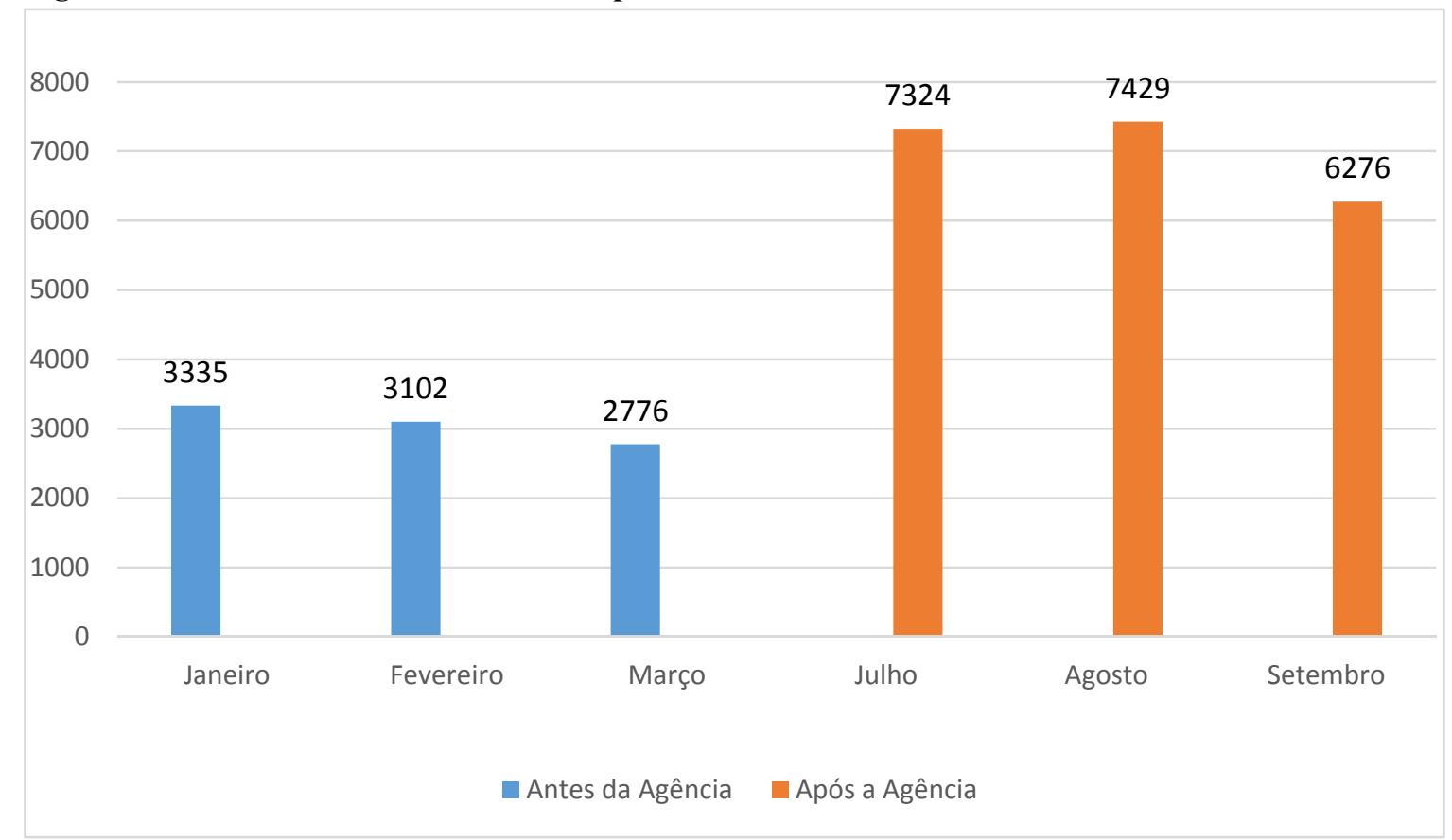

Fonte: Dados da pesquisa.

Como pode-se observar na Figura de visitas, após a contratação o número de visitas aumentou consideravelmente. Se somarmos os três meses e comparar, temos um aumento de aproximadamente $135 \%$, ou seja, o site tem sido muito mais visitado por possíveis compradores após as mudanças sugeridas serem implantadas.

Porém, mais importante do que isso, são as mudanças no faturamento, que é o que observaremos no gráfico a seguir:

Figura 4 - Total de vendas do e-commerce da empresa Alfa.

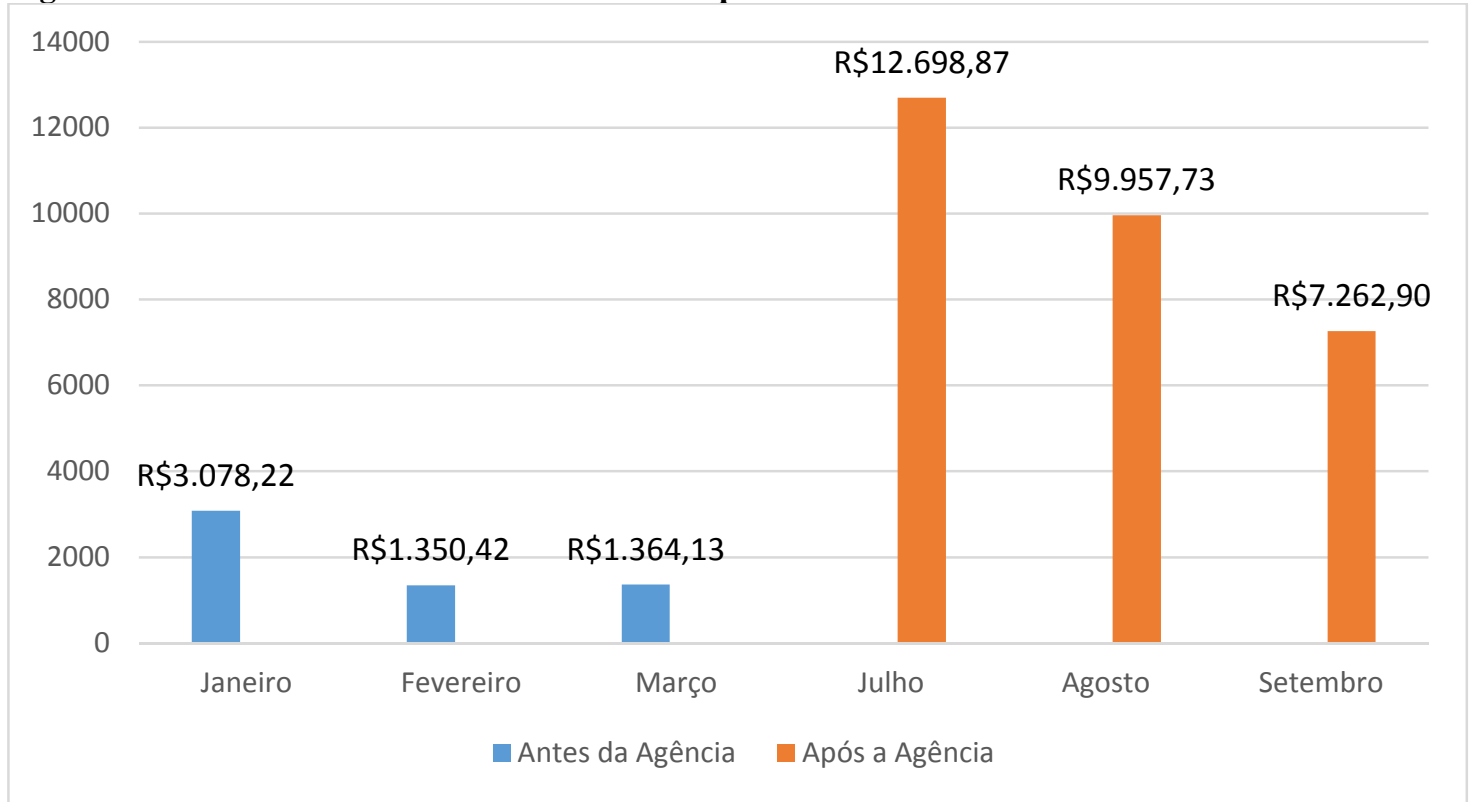

Fonte: Dados da pesquisa.

Tomando como base os números encontrados no gráfico do faturamento, pode-se perceber um aumento de faturamento, comparando a soma dos três meses, de cerca de $420 \%$. Um número relevante para o começo do trabalho de marketing profissional.

R. Eletr. do Alto Vale do Itajaí - REAVI, v. 7, n. 11, p. 01-09, dez., 2018 ISSN: 2316-4190, DOI: $10.5965 / 2316419007112018070$ 
Perguntado sobre quais as dificuldades que o site ainda encontra, e como é feito o controle dos resultados do site, o Entrevistado 1, da empresa Alfa, comenta que:

\begin{abstract}
A maior dificuldade de se trabalhar com o e-commerce com certeza é transformar visitas em vendas, é convencer o cliente de que o produto é bom e que o site traz vantagens para ele. Isso acontece de várias formas conforme conversamos anteriormente, qualidade do produto, preço justo e associação com marketplaces mais conhecidas. Quanto ao marketing digital, não diria que é uma dificuldade e sim uma característica, pois se trata de um trabalho diário de publicações e divulgação, ou seja, um trabalho da construção da marca, e isso é um processo lento (ENTREVISTADO 1).
\end{abstract}

De acordo com o E-COMMERCEBRASIL (2017), as fraudes no comércio eletrônico impactam negativamente os resultados finais das vendas efetivas e, para minimizar as perdas, soluções antifraude aparecem como uma proteção que devem contribuir para o aumento da segurança e das taxas de conversão.

Os dados de visitas e compras devem estar sempre ao alcance da organização, pois eles são o termômetro da qualidade e atratividade do site. Segundo o Entrevistado 1:

Temos total acesso ao Google Analytics, que é um serviço gratuito oferecido pelo Google, na qual podemos acompanhar e monitorar o tráfico no site. Conseguimos ver de qual temos também o acesso ao Google Adwords, que é uma plataforma de publicidade, ali podemos monitorar o controle dos investimentos, podemos contabilizar as impressões e os cliques e principalmente quem realizou alguma conversão no site, como por exemplo, finalizar uma compra. Temos também os resultados obtidos nas publicações impulsionadas do Facebook (ENTREVISTADO 1).

Uma das maneiras mais importantes para transformar os pedidos em vendas é a utilização das plataformas do Google, como as utilizadas pelos empresários. Segundo dados de Bellini e Salvador (2017), cerca de 51\% das transações online acontecem após uma busca no Google. Além disso, a utilização da teoria da "cauda longa" com o intuito de desenvolver estratégias para o público alvo específico, pode trazer benefícios para a empresa estudada.

Por meio dos dados coletados, foi possível encontrar indicativos de que vender produtos pela internet é uma atividade que exige estratégias adequadas para a consecução dos objetivos organizacionais, pois, assim como nas lojas físicas, é necessário satisfazer os clientes, e convencê-los a efetuar a compra. Para isso, a empresa deve continuar oferecendo vantagens e fazendo mudanças que chamem a atenção dos consumidores.

\title{
5. Considerações Finais
}

A presente pesquisa teve como objetivo identificar as estratégias utilizadas para alavancar o e-commerce de uma empresa do ramo de confecção de cama e mesa de Brusque. Nesse sentido, percebemos que essas estratégias visam adequar o site aos vários fatores que influenciam um cliente na hora de efetuar a compra, são eles, preço, qualidade, modo de apresentar o produto, opções de pagamentos e outras vantagens que atraiam sua atenção.

Com base na pesquisa realizada, verificamos que a empresa usou como estratégias em sua plataforma de e-commerce, melhorar a qualidade das fotos de seus produtos, suas descrições e também modificou o layout do site, tornando o mesmo mais funcional e atrativo para os clientes. Além disso, a utilização de marketplaces foi importante para impulsionar as vendas e o reconhecimento da empresa.

Já nas mídias sociais, a empresa teve como estratégia definir o público alvo, ou seja, direcionar as publicações para o público consumidor dos produtos oferecidos no site. Outra opção, foi a criação de campanhas publicitárias em datas especiais para atrair mais cliques.

R. Eletr. do Alto Vale do Itajaí - REAVI, v. 7, n. 11, p. 01-09, dez., 2018 ISSN: 2316-4190, DOI: $10.5965 / 2316419007112018070$ 
Nas plataformas de busca online, a empresa optou como estratégias, a implantação de anúncios pagos com a utilização de links patrocinados, também foram feitos trabalhos de SEO (Search Engine Optimization), que de acordo com a empresa de marketing, é definido como uma forma de aumentar o tráfico de acessos no site, através de uma série de estratégias que melhoram o seu posicionamento nas buscas orgânicas, como por exemplo, o Google.

Todas essas ações de mudança resultaram em um maior número de acessos ao site, cerca de $135 \%$ a mais do que antes da implementação das estratégias de marketing, e, consequentemente, com mais visitas, aumentou também o número de vendas, trazendo um aumento do faturamento em cerca de $420 \%$ após o trabalho da agência de marketing.

Com base no objetivo geral, podemos concluir que a empresa estudada utilizou diferentes ferramentas de marketing digital, tais como anúncios, promoções em datas especiais, divulgação através de redes sociais, formas de apresentar o produto, entre outras coisas, para alavancar o seu e-commerce, e que tais estratégias obtiveram resultados positivos em termo de vendas e faturamento.

Além disso, foram encontrados indicativos de que para auxiliar na melhoria das ferramentas que atraem os clientes, uma boa opção é contratar alguém especializado, no caso em questão, uma agência de marketing. Com a contratação de um serviço profissional como forma de auxílio a empresa conseguiu em pouco tempo aumentar seus indicadores, como número de visitas e total de faturamento. Como sugestões para pesquisas futuras, poder-se-ia estudar empresas que utilizam uma agência de marketing e outras que não utilizam, para comparar suas efetividades.

\section{Referências}

ABIHPEC - Associação Brasileira da Indústria de Higiene Pessoal, Perfumaria e Cosméticos. Crescimento da Indústria de Cosméticos em 2015 Disponível em $<$ http://www.destaketiquetas.com.br/blog/crescimento-da-industria-de-cosmeticos-2015> Acessado em 10 set. 2015.

BARTUNEK, J. M. \& SEO, M. Qualitative research can add new meanings to quantitative research. Journal of Organizational Behavior, v. 23, n.2, mar., 2002.

\section{BELLINI, G.; SALVADOR, M. E-commerce Radar: resultados do mercado de e- commerce do Brasil. São Paulo: Atlas e Abccom, 2017.}

CATEORA, PHILIP R. International Marketing., John L. Graham - 13th edition. 2007

CINTRA, F. C. Marketing Digital: a era da tecnologia on-line Digital Marketing: the age of online technology. INVESTIGAÇÃO, (s. 1.), v. 10, n. 1, p. 7, 2010.

DUARTE, R. Pesquisa qualitativa: reflexões sobre o trabalho de campo. Caderno de Pesquisa, n. 115, p. 139-154, março/2002.

EBIT INFORMAÇÃO. Evolução do Faturamento do E-commerce no Brasil. Dísponivel em: <http://www.ebit.com.br> acessado em 23 de Out de 2017.

E-COMMERCE BRASIL, Menos de 2\% das visitas ao e-commerce viram vendas, segundo pesquisa. Dísponivel em:

https://www.ecommercebrasil.com.br/noticias/menos-2-visitas-e-commerce-vendas/ Acessado em 01 de Nov de 2017

R. Eletr. do Alto Vale do Itajaí - REAVI, v. 7, n. 11, p. 01-09, dez., 2018 ISSN: 2316-4190, DOI: $10.5965 / 2316419007112018070$ 
GABRIEL, Martha. Marketing na era digital: conceitos, plataformas e estratégias. São Paulo: Novatec Editora, 2010.

GIL, A. C. Como elaborar projetos de pesquisa. 4. Ed. São Paulo: Atlas, 2002.

GROSSMANN. L .O. Dois terços do comércio eletrônico são por smartphones, diz Ibope. Disponível em: http://www.convergenciadigital.com.br/cgi/cgilua.exe/sys/start.htm?UserActiveTemplate=site \&infoid=35170\&sid=> Acessado em 13 de Nov de 2017.

HELLER, Eva. A psicologia das cores. São Paulo: Editora GG, 2013.

IDESIS, Leandro. E-commerce, E-business, E-o que?, Disponível em: http://www.ecommerce.org.br/artigos/ecommerce_ebusiness.php> Acesso em: 30 mar. 2017

KOTLER, P. Administração de Marketing. 10 ed. São Paulo, Prentice Hall. 2008.

LAIER. A. P. Ebit prevê crescimento de $12 \%$ no faturamento do comércio eletrônico no Brasil em 2017. Disponível em: $<$ http://epocanegocios.globo.com/Tecnologia/noticia/2017/02/epoca-negocios-ebit-prevecrescimento-de-12-no-faturamento-do-comercio-eletronico-no-brasil-em-2017.html $>$ Acesso em 26 Ago. 2017.

MALLETA, Bruno. E-commerce de moda: segunda versão 2013. Disponível em: $<$ http://www.slideshare.net/ebricks/e-bricks-msensemoda2013>. Acesso em: 06 out. 2013

MANZINI, E. J. A entrevista na pesquisa social. Didática, São Paulo, v. 26/27, p. 149-158, 1990/1991.

MINAYO, M.C. de S. O desafio do conhecimento: Pesquisa Qualitativa em Saúde. São Paulo. 2010. Hucitec-Abrasco. 12. edição.

MORAES, Tiago. História do E-Commerce no Brasil. Disponível em: $<$ http://www.agenciaeplus.com.br/historia-do-e-commerce-no-brasil/> Acesso em: 25 jun. 2017

NAKAMURA, Rodolfo Reijiro. E-commerce na Internet: fácil de entender. São Paulo: Érica, 2001.

NOGUEIRA, J. Marketing Digital: Conceito e Definição. Disponível em: < https://www.administradores.com.br/artigos/marketing/marketing-digital-conceito-edefinicao/76673/> Acessado em 23 de Out 2017.

O’BRIEN, James A. Sistemas de Informação: e as decisões gerenciais na era da Internet. 2. ed. São Paulo: Saraiva, 2004.

PARENTE, J. Varejo no Brasil: Gestão e estratégia. 1ed. São Paulo: Atlas, 2000. 
PINHO. J. B. (org) Comunicação em Marketing: Princípios da comunicação mercadológica. $3^{\text {a }}$ Edição. Campinas, Papirus, 2000.

PROFISSIONAL DE E-COMMERCE. Perfil do consumidor online: Quem compra na internet? Dísponivel em: $<$ http://www.profissionaldeecommerce.com.br/perfil-doconsumidor-online-quem-compra-na-internet/> Acessado em 01 de Nov de 2017.

SANTOS, N. B. Dos. Marketing digital e o e-commerce: um estudo de caso em uma loja virtual de autopeças. 2017. Monografia de Conclusão de Curso - UNESC, Criciúma, 2017.

SEBRAE. Panomara do ecommerce no Brasil. Disponível em: < https://www.sebrae.com.br/sites/PortalSebrae/artigos/conheca-o-panorama-do-e-commerceno-brasil,66d975e0dc256510VgnVCM1000004c00210aRCRD> Acesso em 05 de Out. 2017.

TURCHI, Sandra R. Estratégias de marketing digital e E-commerce. São Paulo: Atlas, 2012.

VALENTE. J.. Relatório aponta Brasil como quarto país em número de usuários de internet. Dísponivel em: < http://agenciabrasil.ebc.com.br/geral/noticia/2017-10/relatorioaponta-brasil-como-quarto-pais-em-numero-de-usuarios-de-internet $>$ Acessado em 01 de Nov de 2017.

VERGARA, Sylvia Constant. Projetos e relatórios de pesquisa em administração. 14. ed. São Paulo: Atlas, 2013.

YESIL, Magdalena. Criando a loja virtual. Rio de Janeiro: Infobook, 2000.

WEBJUMP. Crescimento do E-commerce no Brasil. Disponível em: $<$ http://www.webjump.com.br/loja-virtual-magento/crescimento-e-commerce-brasil/> Acesso em 26 d Ago. 2017. 